\title{
Projeto Geo-Escola: Disseminação de Conteúdos de Geociências por Meio do Computador para Docentes de Ciências e Geografia no Nível Fundamental em Jundiaí-Atibaia, SP
}

\author{
Celso Dal Ré Carneiro (cedrec@ige.unicamp.br) e Ronaldo Barbosa \\ Departamento de Geociências Aplicadas ao Ensino - Instituto de Geociências - UNICAMP \\ Caixa Postal 6.152, CEP 13083-970, Campinas, SP, BRA
}

Recebido em 12 de maio de 2004; aceito em 10 de março de 2005

Palavras-chave: divulgação científica, ensino, Geociências, computadores.

\section{RESUMO}

O Projeto Geo-Escola visa disponibilizar dados geológicos, imagens e mapas, de uma dada região, em formato de material didático com suporte em computador, a professores de ensino fundamental e médio. Encontra-se em avaliação nesta etapa da pesquisa o primeiro módulo-piloto, planejado para instituições de ensino fundamental, públicas e particulares, da região entre Jundiaí e Atibaia (SP). Os trabalhos iniciaram-se por uma consulta aberta, formulada ao conjunto de escolas da região, buscando-se contatar os professores das disciplinas de Geografia e Ciências. Levantaram-se dados sobre a infra-estrutura de microcomputadores existente nas escolas. Mais de $85 \%$ das 49 escolas que responderam ao questionário dispõem de equipamentos de informática para apoio pedagógico e alguma forma de acesso à Internet. Os produtos despertaram grande interesse: os 108 professores que responderam à consulta utilizam recursos audiovisuais, interessam-se em aplicar temas geocientíficos nas disciplinas e valorizam a abordagem da dinâmica ambiental em suas aulas. Um exame comparativo dos Parâmetros Curriculares Nacionais das áreas de Geografia e Ciências com os conteúdos efetivamente ministrados na escola fundamental nessas disciplinas permite concluir que, independentemente da valorização oficial da abordagem da realidade local em Ciências e Geografia, historicamente os temas geocientíficos sofreram certo abandono. O Projeto Geo-Escola, inserido nesse contexto, ao disponibilizar via CD-ROM e Internet dados e ferramentas abertas, estimula o uso mais democrático dos equipamentos e programas e pode contribuir para a atribuição de novos papéis para professor e aluno: "professor-autor" e "aluno-autor", podendo ser reproduzido e adaptado a outras realidades regionais. Os resultados preliminares da consulta a 168 escolas do módulo Jundiaí-Atibaia sugerem que o projeto possa resultar em iniciativas similares em outras regiões.

Keywords: scientific divulgation, teaching, Geosciences, computers.

\section{ABSTRACT}

The Geo-School project aims at the computer-aided dissemination of geological data, images and maps of a given region to elementary school teachers. The first pilot-module, planned for public and private institutions of elementary education, is being evaluated at this stage of the research. It was developed for the region between Jundiaí and Atibaia (SP). The work started with an open inquiry, sent to Geography and Sciences teachers of the study area. A survey of the existing infrastructure was also included in the investigation. The preliminary results of research on the 132 public and 36 private schools of the Jundiaí-Atibaia region indicate that more than $85 \%$ of the 49 schools that answered the questionnaire make use of computer equipment for pedagogical support and limited access to the Internet. The demand for the potential products is great, as long as all the 108 teachers who participated in the inquiry use audiovisual resources and are interested in applying geoscience subjects to the course they teach. The Geo-School project uses CD-ROM and Internet resources to deliver free software tools. It stimulates a more democratic use of the equipment and programs and can contribute to the development of new roles, such as "teacher-authors" or as "student-authors". The results of the preliminary consultation made to 168 schools of the Jundiaí-Atibaia module suggest that the Geo-School project may stimulate similar initiatives elsewhere. 


\section{INTRODUÇÃO}

Vive-se uma época marcada por variados e complexos aparatos tecnológicos de observação e monitoramento da Terra, que oferecem nova visão da dinâmica dos sistemas integrados que a compõem. Conceitos ligados às Geociências devem ser crescentemente considerados na educação pois permitem tratar tais informações (Carneiro et al., 2004) e constituem, cada vez mais, um conhecimento essencial da dinâmica do planeta para que qualquer cidadão seja capaz de se localizar nesse meio e compreender as linhas mestras de funcionamento do meio natural.

As chamadas Ciências Geológicas contemplam temas que estimulam a reflexão sobre as relações do homem com o planeta, favorecem a adoção de novas atitudes e valores e contribuem para que o aluno se torne um "cidadão capaz de avaliar e julgar as ações de interferência, ocupação e uso do ambiente e de seus materiais e agir com consciência e responsabilidade nesta questão" (Parâmetros Curriculares Nacionais do Ensino Médio - PCNEM, Brasil, 1999). Ademais, a Geologia facilita a inserção, nas aulas, de temas da região onde os alunos vivem, despertando a compreensão de aspectos familiares ou trazendo respostas a indagações ou curiosidades. Também sob o ponto de vista da divulgação científica, uma vez que a divulgação científica pode complementar a educação básica, a difusão de conceitos geológicos pode contribuir para que a população brasileira tenha acesso a informações decisivas para suas "necessidades de saúde, educação, formação política e participação nos processos sociais" (PRO-SCIENTIÆ NJR/ECA/USP, 2002).

Entretanto, embora previstos nos Parâmetros Curriculares Nacionais do ensino fundamental, historicamente os conteúdos geológicos ministrados em disciplinas de Ciências e Geografia foram desprestigiados, perderam importância relativa e, conseqüentemente, sofreram notável mudança de tratamento. Em teoria, persiste a valorização oficial dos aspectos da realidade natural em Ciências e Geografia mas, na prática, houve um abandono da abordagem de temas geocientíficos locais e regionais (Barbosa, 2003).

No ensino fundamental, Campos (1997) assinala que o programa de Ciências, dividido segundo os tópicos ar, água e solo, é fragmentário e não permite que o professor "descreva aos seus alunos o mundo em que vivemos, sua origem, evolução e destino". O livro didático poderia sanar algumas dessas deficiências, mas falta "uma visão integrada da Terra e das interações dos sistemas que a compõem" (Carneiro et al., 2004).

Toledo (2002) assinala existir no ensino médio uma fragmentação, já que os PCNEM consideram a Biologia, Física, Química, Geografia, História e Filosofia como "campos do conhecimento que contribuem para o estudo da dinâmica ambiental, possibilitando ao aluno relacionar conceitos aprendidos nessas disciplinas, numa conceituação mais ampla de ecossistema". Nessas disciplinas, os conceitos de Geociências estão dispersos em lugar de haver uma visão integrada, pois eles aparecem segundo abordagens específicas e uma ótica seletiva e particular às disciplinas. Tal dissociação é improdutiva (Toledo, 2002), pois:

a. perde-se de vista a noção de interdependência entre os processos;

b. não se apresenta o ciclo natural global;

c. não se destaca o tempo geológico como fator inerente à sucessão dos processos naturais;

d. priva-se os estudantes da oportunidade de utilizar o "laboratório Terra", para compreender e contextualizar os processos físicos e químicos, e ainda a origem e evolução da vida, delineada ao longo do tempo por meio da evolução dos ecossistemas (Toledo, 2002).

\section{Papel educacional do computador}

O computador tem sido utilizado quer como instrumento de acesso pela web a recursos, informações e dados, quer como laboratório prático de novos programas e jogos educativos. Há ampla difusão de conhecimentos geocientíficos na web, mas faltam dados sobre a existência de espaços para o devido tratamento dessas informações em instituições de ensino (Durbin, 2002). O investimento das escolas e do setor público responsável pela educação tem favorecido o acesso a recursos externos à sala de aula (Carneiro e Barbosa, 2002a), pois a informática proporcionou verdadeira explosão de alternativas de acesso à informação especializada e a recursos educacionais que ajudam o ensino-aprendizagem. Constitui um desafio avaliar se tal expansão estimulou a elaboração de material de apoio, atualização e renovação de livros didáticos e paradidáticos, graças ao crescente volume de informações sobre o planeta disponíveis na web.

O professor do ensino fundamental é "um generalista que deveria conhecer com clareza e precisão os conceitos básicos extraídos da grande massa de informações gerada a cada ano" (Meis et al., 1997). A tarefa de selecionar as noções fundamentais, caso fosse deixada a cargo do professor, revelar-se-ia impossível. A universidade assume, pois, um papel central na tarefa de decodificar o saber e promover interação entre professores universitários e professores do ensino básico (Meis et al., op. cit.). Nesse contexto, enquanto o acesso às ferramentas computacionais é relativamente fácil, os docentes raramente têm acesso a informações sobre o ambiente local, exceto durante cursos de capacitação e aprimoramento.

O Projeto Geo-Escola nasceu com a preocupação de avaliar conteúdos geológicos essenciais para compor o 
universo de temas da realidade local que possam ser tratados com apoio do computador no ensino médio e fundamental (Carneiro e Barbosa, 2002b). O primeiro módulo, aqui descrito e discutido, busca auxiliar o trabalho do professor de Ciências e Geografia da escola fundamental ( $5^{\mathrm{a}}$ a $8^{\mathrm{a}}$ séries) de um total de dez municípios da região entre Jundiaí e Atibaia, Estado de São Paulo. Foi proposto fornecer informações sobre temas locais (e regionais) que pudessem ser utilizados para desenvolvimento de programas das respectivas disciplinas. Nessa fase, pesquisou-se tanto o interesse desses professores por conceitos básicos, como pelos temas regionais.

\section{OBJETIVOS}

O Projeto Geo-Escola enfatiza algumas alternativas de uso do computador como ferramenta educativa no ensino de Geociências. O presente texto objetiva apresentar a concepção do projeto, tendo em vista duas hipóteses de trabalho iniciais:

a. a difusão de informações sobre a Geologia e a dinâmica ambiental de uma dada região tem interesse direto para os docentes que ali exercem seu trabalho;

b. é pouco provável que exista uma região, no país, sobre a qual tenha sido produzido material didático em Geociências, disponibilizado e compartilhado por professores de diferentes escolas.

Uma dificuldade básica para que a história geológica de uma dada região e sua dinâmica ambiental sejam explorados no trabalho diário de professores são as eventuais deficiências conceituais em Geociências destes últimos. Geo-Escola privilegia, no ensino fundamental, professores das disciplinas Ciências e Geografia; no ensino médio podem ser incluídas outras, como as disciplinas de Biologia, Física, Química ou Geografia. O projeto, organizado em módulos, deve conciliar o tratamento de aspectos fundamentais com a oferta de temas geológicos mais especializados. Conceitos geológicos básicos são, portanto, um suporte para tratamento de conhecimentos específicos da região abordada; o acervo de materiais didáticos resultante pode ser, teoricamente, aproveitado em diferentes disciplinas.

\section{Pressupostos}

Dentre os estudos acadêmicos na área de tecnologia educacional, há muitos trabalhos voltados para o ensinoaprendizagem em Geociências com emprego de Informática (e.g. Pinto et al., 1998; Pardo, 1996). O Projeto Geo-Escola tem como base os seguintes pressupostos (Carneiro e Barbosa, 2002a), que constituem referência da pesquisa:
1. desde a extinção da antiga disciplina de História Natural e a criação de Biologia, na década de 60, inexiste no Brasil, como em outros países, uma disciplina específica de Geociências (ou Geologia) abrigando os conteúdos correspondentes;

2. os conhecimentos de Geociências veiculados no ensino médio e fundamental no Brasil limitam-se a inserções em uma série de disciplinas, como Geografia e Ciências;

3. predomina a aula expositiva, eventualmente ilustrada pelo professor;

4. desconhece-se o grau de utilização, pelos professores, do computador como ferramenta auxiliar na produção de material didático, nem há clareza quanto às respostas que este recurso pode desencadear.

\section{A área estudada}

O exemplo aqui discutido compreende um módulo do projeto voltado para escolas públicas e particulares da região compreendida entre os municípios de Jundiaí, Atibaia, Mairiporã, Franco da Rocha, Francisco Morato, Cajamar, Várzea Paulista, Jarinu e Campo Limpo Paulista (Figura 1), cidades próximas à região metropolitana de São Paulo.

\section{Fontes de informação}

O projeto depende da participação de professores e pode interferir na sua prática profissional. Ademais, o Projeto GeoEscola depende diretamente de informações e mapas atualizados da região considerada, para que sejam produzidos recursos que possibilitem o uso do computador como ferramenta educativa.

Na Unicamp, desde 1996, docentes e estudantes têm elaborado mapas geológicos, geomorfológicos, estruturais e de ocupação de uma região que compreende partes dos municípios situados entre Jundiaí e Atibaia, sob coordenação de um dos autores (CDRC). Os mapas elaborados pela equipe do projeto constituem uma base geológicogeotécnica georreferenciada (Carneiro et al., 2000), composta por mapas em escalas de semidetalhe, a saber: 1:25.000 - mapas geológico (Carneiro, 2001) e geomorfológico (Souza e Carneiro, 2002a, 2002b; Carneiro e Souza, 2003) e 1:10.000, a base plani-altimétrica produzida a partir de folhas vetorizadas do Projeto Macro-Metrópole. A par do conhecimento cartográfico, o Projeto Jundiaí-Atibaia vem acumulando informações técnicas sobre a região e tem gerado roteiros didáticos para estudos ambientais (Oliveira e Carneiro, 2001, 2002).

Os mapas e informações podem ser utilizados em salade-aula, persistindo porém duas dificuldades: 


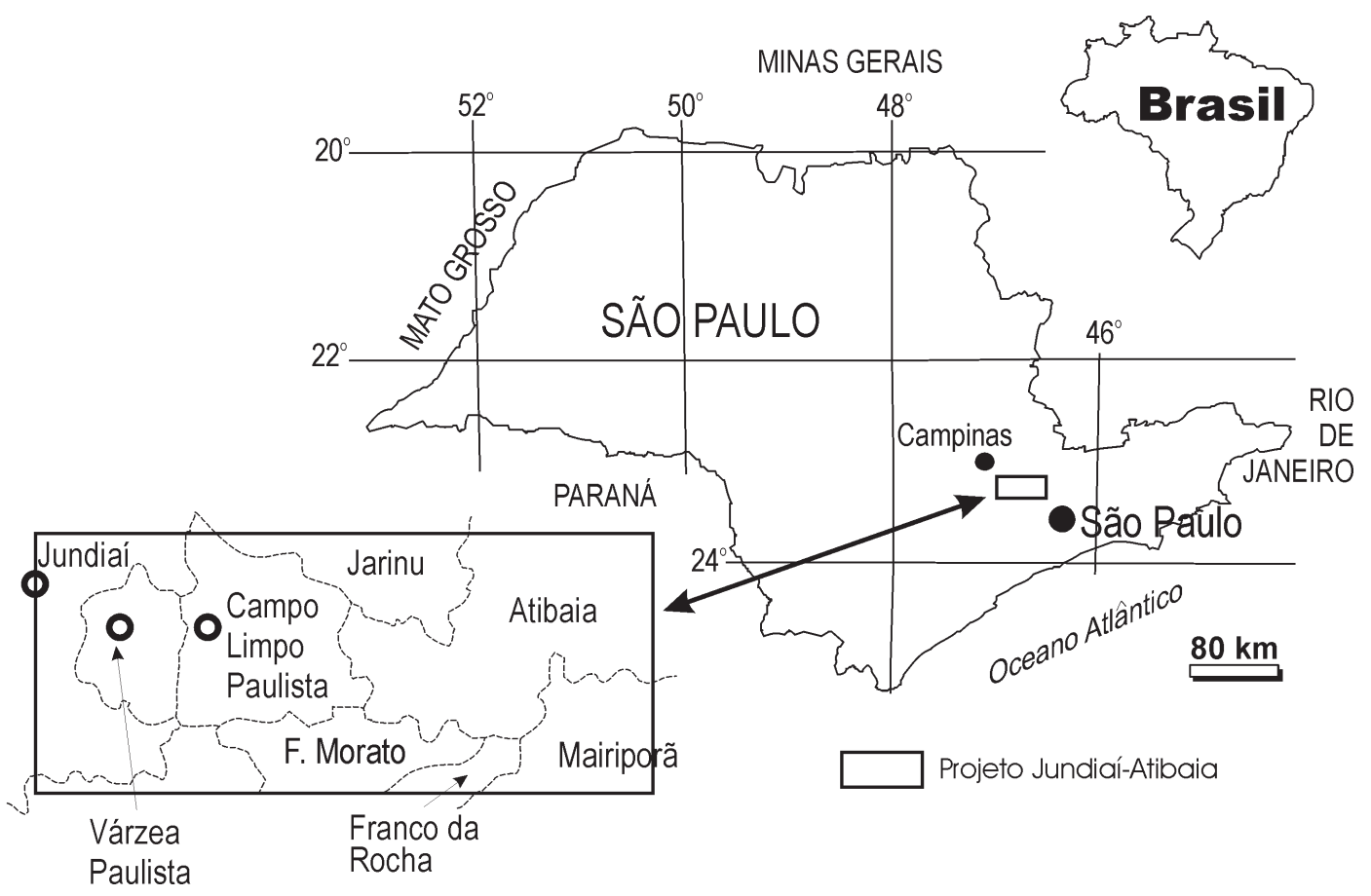

Figura 1. Localização da área estudada no Estado de São Paulo.

1. excessiva dependência de textos técnicos para tratar de conceitos especializados;

2. dificuldade de se realizar simplificações que possam empobrecer e descaracterizar o grau de conhecimento atual da dinâmica natural na área.

\section{As rochas e o relevo da região considerada}

Acumula-se um acervo notável de exemplos da influência antrópica na região de Jundiaí-Atibaia e das conseqüências de ocupações mal-planejadas sobre o ambiente, já que a pressão induzida pelo crescimento urbano da região metropolitana de São Paulo é intensa, complexa e desigual (Carneiro, 2001). A ocupação foi em parte controlada pelas limitações do substrato litológico, formas de relevo, dinâmica climática (sobretudo as chuvas) e patrimônio ambiental existente; assim, as dinâmicas regional e local revelaram-se um "laboratório" privilegiado para o estudo das relações do homem com o ambiente.

A pesquisa permitiu identificar diversas situações de risco geológico na região de Jundiaí-Atibaia; diferentes impactos ambientais haviam sido avaliados, mormente em Campo Limpo e Francisco Morato (Carneiro, 1999). Os impactos refletem os contrastes entre formas de relevo presentes e práticas construtivas associadas a certos padrões de ocupação urbana.
Situações particulares da periferia de Jundiaí, Franco da Rocha e Atibaia podem ser igualmente aproveitadas pelos professores da região. Em resumo, tem-se um contexto gerador de situações críticas, dispersas na área, com ampla documentação de exemplos da influência das estruturas e das rochas na dinâmica superficial.

O substrato rochoso é composto essencialmente por rochas cristalinas foliadas e intrusões graníticas, cuja evolução processou-se entre o Paleoproterozóico e o Eopaleozóico. Durante esse longo intervalo de tempo desenvolveram-se xistos, filitos, quartzitos, metarenitos e diversos tipos de gnaisses. No Neoproterozóico o conjunto foi deformado, metamorfizado, cortado por zonas de milonitização e penetrado por corpos ígneos. No Eopaleozóico desenvolveram-se transcorrências e reativações de falhas antigas e, no Terciário, o soerguimento regional permitiu que a erosão modelasse o relevo, acompanhada pela formação de coberturas sedimentares e pelo posterior aprisionamento tectônico de pequenos restos de sedimentos de idade terciáriaquaternária nas áreas urbanas de Jundiaí e Atibaia.

A instalação da rede hidrográfica local faz parte da etapa evolutiva mais recente. O relevo integra a província do Planalto Atlântico, sendo dominantemente constituído de morros e porções mais restritas de colinas e zonas serranas. Foram mapeadas distintas formas de relevo em dois domí- 
nios, delimitados por duas zonas geomorfológicas: a transição entre a Serrania de São Roque e a Morraria de Jundiaí. São feições controladas pela influência da estrutura e da resistência diferencial das rochas à erosão sobre o relevo (Almeida, 1964; IPT, 1981).

\section{MÉTODOS}

Para investigar o uso do computador como ferramenta educativa de Geografia e Ciências no ensino fundamental, operou-se no Projeto Geo-Escola dentro de um modelo de arquitetura aberta. O módulo aqui descrito, Jundiaí-Atibaia, teoricamente pode ser adaptado a outras realidades regionais, sob a perspectiva de que a disponibilização de dados, imagens e mapas locais da região onde o professor atua - e que provavelmente são familiares aos alunos - favorecerá abordagens em sala-de-aula.

Motivados pela inexistência de disciplinas específicas de Geologia/Geociências no nível fundamental no Estado de São Paulo, tal como ocorre no restante do Brasil, os trabalhos iniciaram-se por meio de uma consulta aberta, formulada ao conjunto de escolas da região e dirigida aos professores das disciplinas de Ciências e Geografia, para que indicassem temas de Geociências de interesse para apoiar atividades escolares.

\section{Etapas}

\section{Avaliação das fontes de informação disponíveis e estudos complementares}

A primeira etapa de execução do projeto envolveu o levantamento de informações geológicas e ambientais dos municípios envolvidos. Esta etapa estabeleceu também orientações sobre mapeamentos e estudos complementares que pudessem ser conduzidos, dependendo da necessidade, nesse mesmo projeto ou em outra pesquisa paralela.

\section{Questionário dirigido às instituições de ensino da área}

O projeto, para ser viabilizado, dependeu da colaboração do maior número possível de professores de instituições dos municípios. Foi enviado um questionário preliminar às escolas da região, permitindo-se livre reprodução do instrumento de consulta, precisamente para aumentar o leque de docentes atingidos; as respostas foram devolvidas por correio ou fax. O retorno do questionário respondido representou a inscrição automática da escola e do professor no projeto. Assumiu-se o compromisso de enviar ao professor da instituição participante, em questão de meses, sem ônus, o CD-ROM educativo e dados adicionais de utilização.

\section{Objetivos do levantamento}

O questionário objetivou:

a. obter uma medida do interesse dos professores por temas geocientíficos;

b. definir um grupo de escolas e professores com interesse de participar no projeto, ou seja, em incluir o uso de programas em suas aulas;

c. a seleção de temas em Geociências a serem implementados nos programas de computador.

\section{Temas pesquisados}

Diversos temas foram propostos para investigação, tendo em vista que aqueles de maior interesse seriam priorizados para produção de material didático pela equipe. Foi fornecida aos professores das escolas da região uma lista de 15 temas, com a finalidade de conhecer aqueles de interesse mais imediato e procurando-se avaliar ao mesmo tempo as demandas de informação básica e conhecimento especializado em Geociências. O professor teve liberdade de pontuar (em uma escala que variou entre 1 e 5 pontos) os mais relevantes dentre os seguintes temas:

1. relevo, topografia, localização espacial, mapas;

2. minerais e classificação de rochas;

3. formação do Universo e da Terra;

4. eclipses, meteoros, estações do ano, dados sobre o sistema solar e seus planetas;

5. história geológica do planeta;

6. tempo geológico;

7. ciclos da natureza;

8. água, rios e ciclo hidrológico;

9. esferas da Terra, placas tectônicas, vulcões, terremotos;

10. umidade, energia e clima;

11. intemperismo e solos, tipos de solo, movimentos do solo;

12. riscos de acidentes naturais e ocupação urbana;

13. Geologia e evolução geológica da região de JundiaíAtibaia;

14. relevo da região de Jundiaí-Atibaia e problemas de ocupação urbana;

15. estudos do meio e trabalhos de campo na região de Jundiaí-Atibaia.

\section{Material didático inicial em CD-ROM}

Com base nos resultados da consulta, foi elaborado um conjunto de programas na forma de seqüências de telas prontas, em esquema de slide-show, e um editor capaz de gerar novas seqüências, a partir das anteriores, utilizando- 
se imagens internas ou externas aos próprios programas (Carneiro e Barbosa, 2003). Incluiu-se um pequeno banco de imagens e fotografias no CD-ROM, acompanhado de informações sobre os aspectos particulares ali apresentados, para facilitar o uso desses materiais pelo professor. As etapas envolvidas foram:

a. envio do material didático (CD-ROM) às instituições pelo correio, em nome dos professores de Ciências e Geografia;

b. utilização do CD-ROM pelos professores e alunos durante pelo menos um semestre letivo;

c. realização de consultas, coleta de depoimentos e avaliação do emprego dos programas.

\section{Avaliação do material fornecido}

A avaliação do uso dos programas de computador envolveu três etapas distintas:

a. respostas a um segundo questionário dirigido aos mesmos docentes;

b. entrevistas pessoais com os professores;

c. participação direta dos professores no site de apoio ao projeto.

\section{RESULTADOS DO MÓDULO JUNDIAÍ-ATIBAIA}

Com base nos documentos e produtos existentes do Projeto Jundiaí-Atibaia, foi produzida uma consulta formal às 168 escolas da região, dentre as quais 132 são públicas e 36 particulares (Tabela 1). Os resultados da consulta a professores de Geografia e Ciências, descritos por Carneiro e Barbosa (2002a), indicam ter sido recuperada importante informação acerca da disponibilidade de salasambiente para ensino em computador, contendo número razoável de equipamentos. O levantamento consistiu em uma lista de temas, esclarecendo-se que os docentes deveriam selecionar aqueles considerados prioritários para compor um CD-ROM e nova versão do site do projeto, cuja versão preliminar está disponível no seguinte endereço: http://www.ige.unicamp.br/ jundiati.

\section{Priorização de temas}

Houve grande receptividade dos professores à consulta, resultando um volume significativo de respostas (108, dentre 49 escolas). Dentre os variados temas na lista inicial de 15 propostos para investigação, o professor teve liberdade de pontuar aqueles que considerasse mais interessantes ou úteis para suas aulas. Nenhum tema sugerido foi rejeitado ou obteve baixa indicação. Houve, entretanto, certa dispersão de escolhas que sugere, sobretudo, acentuado interesse por temas ligados à dinâmica geral do planeta, mas ao mesmo tempo revela obstáculos e facilidades operacionais para a pesquisa. As 37 escolas públicas e 12 particulares, em um total de 49 (Tabela 1), representam cerca de $28 \%$ das instituições consultadas; em média, houve participação de pouco mais de dois professores por instituição. Em 26 questionários, 12 ou mais tópicos (de um total de 15) foram assinalados pelos professores como de "alto interesse".

Os temas de maior interesse, cuja produção acabou sendo priorizada, são:
1. água e ciclo hidrológico;
2. ciclos da natureza;
3. acidentes naturais;
4. trabalhos de campo na região de Jundiaí-Atibaia.

\section{Importância dos conteúdos geológicos no ensino fundamental}

Os resultados obtidos na consulta de Jundiaí-Atibaia reforçam a necessidade de se abordar temas geológicos no ensino fundamental (Carneiro et al., 2004). A partir dessa visão, pode-se retomar discussões ocorridas há mais de duas décadas no país. Paschoale et al. (1981) justificaram tal inserção nas escolas de $1^{\circ}$ e $2^{\circ}$ graus, com os argumentos de que a Geologia:

1. contribui significativamente para o conhecimento científico da natureza;

2. possui características que a tornam independente em relação a outras Ciências, como a Geografia Física, a Química e a Física;

Tabela 1. Escolas consultadas e participantes do Módulo Jundiaí-Atibaia.

\begin{tabular}{lcccccc}
\hline \multicolumn{1}{c}{ Escolas } & Públicas & $\%$ & Privadas & $\%$ & Total & $\%$ \\
\hline Inicialmente consultadas & 132 & 78,6 & 36 & 21,4 & 168 & 100,0 \\
Participantes da pesquisa & 37 & 22,0 & 12 & 7,1 & 49 & 29,2 \\
\hline
\end{tabular}


3. assume especial relevância no momento histórico vivido pela humanidade, sobretudo devido aos problemas dos recursos naturais e do equilíbrio ambiental;

4. assume uma perspectiva integradora dos conhecimentos científicos da natureza.

\section{O produto fornecido em CD-ROM}

Com base nos resultados da consulta, foi produzido um material didático, na forma de slide-show, em CD-ROM, contendo ainda textos de apoio e fotografias. Foram preparadas apresentações sintéticas sobre os dois temas considerados mais relevantes pelos docentes de Ciências e Geografia: Água e Ciclo Hidrológico e Ciclos da Natureza, que podem ser operadas diretamente em um programa de edição de apresentações, chamado Editor (Figuras 2 e 3). O Projeto Geo-Escola pretende fomentar e propiciar a interação entre os educadores via Internet, naturalmente contando com o apoio de obras disponíveis no mercado editorial, como Carneiro (2000) e Teixeira et al. (2000), dentre outras.

Uma vez que a etapa de mapeamento geológico gerou muitas informações e fotos de campo, decidiu-se abordar parcialmente o terceiro tema selecionado, Acidentes Naturais, por meio de fotografias. Para viabilizar essa alternativa forneceu-se um programa de visualização, denominado Álbum de Fotografias (Figura 4), que permite observar as fotos, determinar com rapidez sua localização em mapas e consultar as respectivas descrições.

A etapa de avaliação do CD-ROM educacional submetido aos docentes por meio do Projeto Geo-Escola ainda está em andamento. Para avaliar a efetividade do projeto pretende-se adotar como referência a produção de materiais didáticos por parte dos professores, passo importante para a inclusão da realidade local na sua prática com os alunos. Essa avaliação deverá levar em conta os seguintes parâmetros:

a. utilidade dos materiais em diferentes situações de ensino-aprendizagem e diversas séries escolares;

b. estudo das relações do homem com o planeta, com destaque particular para aspectos presentes na região onde os alunos vivem;

c. possibilidade de se aproveitarem dados básicos sobre a história geológica da região e sua dinâmica ambiental em sala-de-aula;

d. avaliação da alternativa de se incrementar os estudos de campo (os chamados estudos do meio) considerando-se informações de natureza geológica.

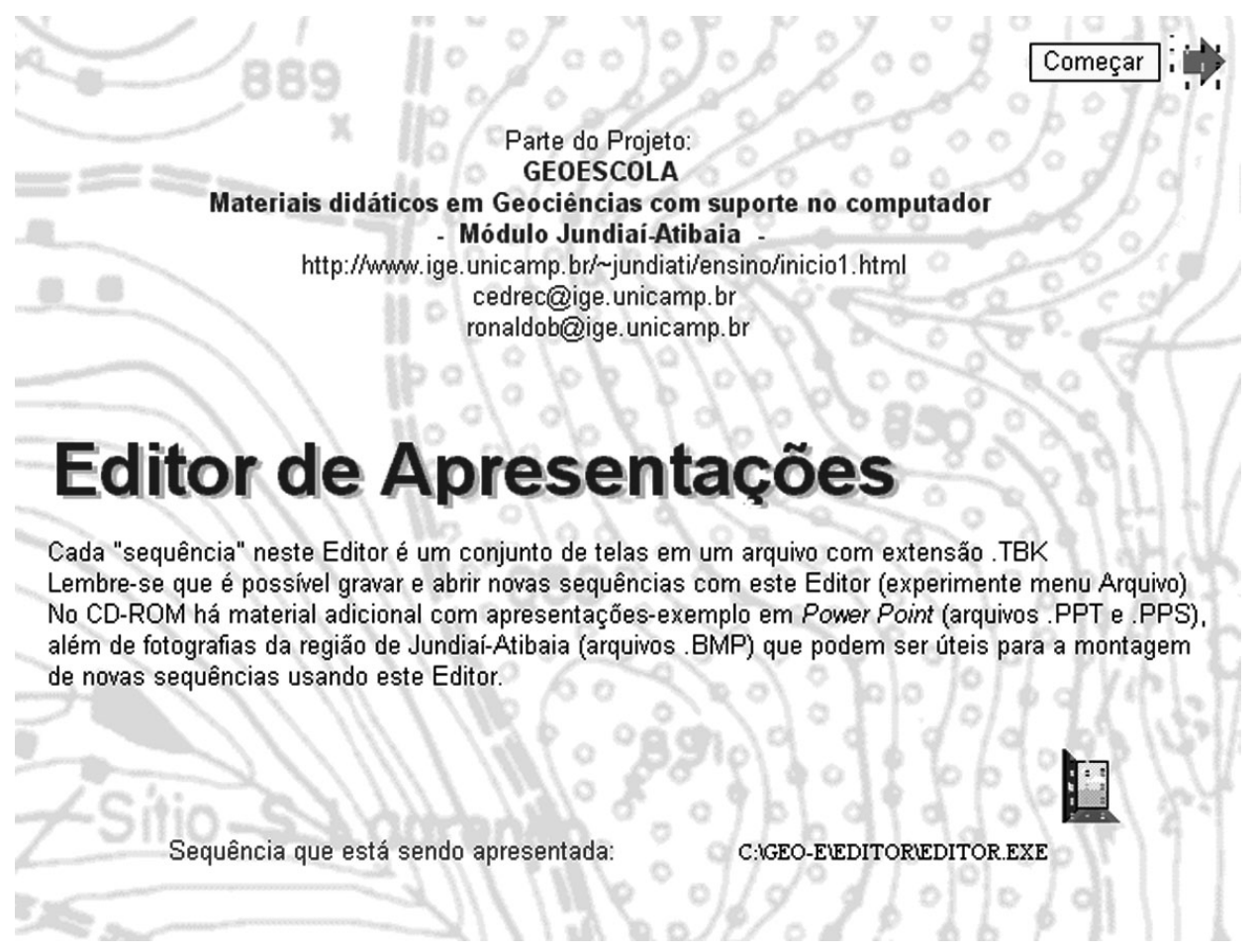

Figura 2. Tela de abertura do Editor de Apresentações. 


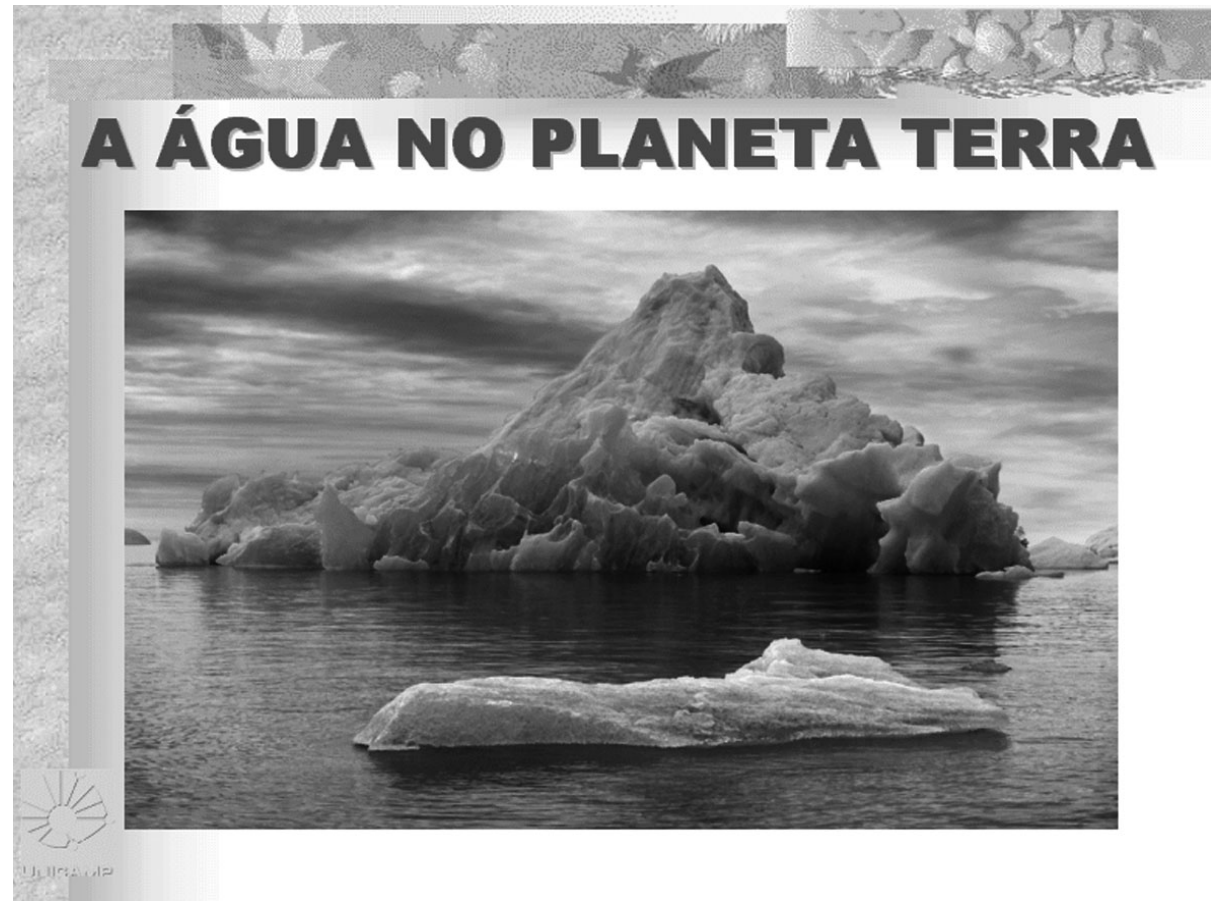

Figura 3. Aula sobre "água" no Editor de Apresentações.

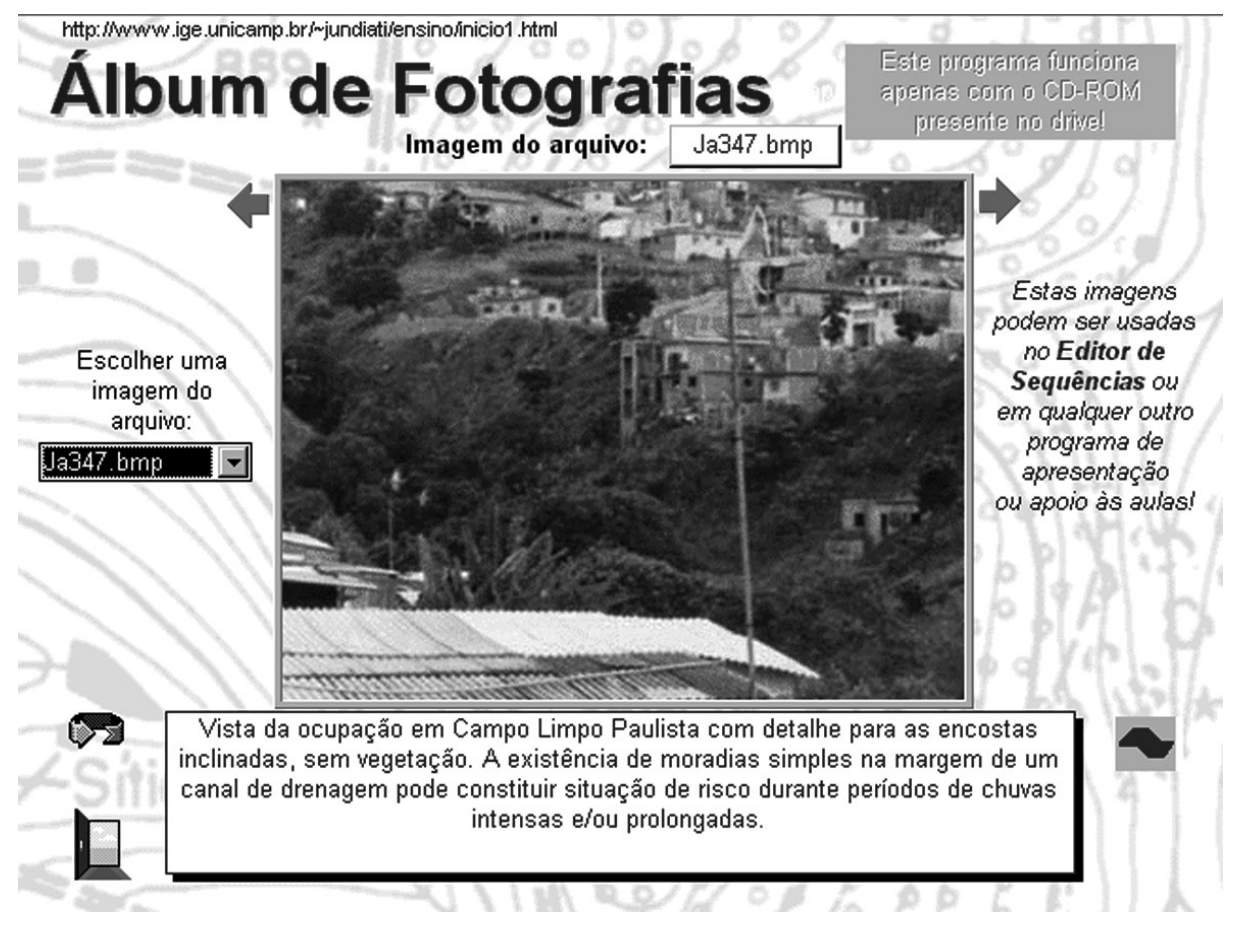

Figura 4. Exemplo de imagem aberta no Álbum de Fotografias. 


\section{DISCUSSÃO}

\section{Importância do computador no ensino de Geociências}

O Projeto Geo-Escola depende efetivamente de que os usuários tenham condições de acessar os materiais e reproduzi-los a partir de equipamentos encontrados nas próprias escolas; são elementos que norteiam o planejamento da etapa de produção e geração de material didático, com base nos temas de Geociências selecionados pelos professores.

O computador disseminou-se como ferramenta de produção de material didático para sala-de-aula. A utilização direta, em apresentações, pode envolver periféricos cujo custo pode se tornar inacessível para a grande maioria das escolas; um monitor de um desktop ou um laptop, acoplado com aparelhos de TV, pode representar uma solução sofisticada e inacessível. Diapositivos e transparências são mais familiares e criam menor número de problemas.

A percentagem de docentes que utiliza recursos audiovisuais (incluindo-se o emprego de vídeo) é alta (101 dentre os 108 consultados). Os números equivalem a 93,5\% da amostra, contra 6,5\% dos professores que não utilizam recursos audiovisuais. O interesse por recursos audiovisuais é igualmente alto conforme respostas de 93 professores (86\%).

Dentre as 49 escolas que responderam aos questionários (37 públicas e 12 particulares), os dados de disponibilidade e uso de equipamentos didáticos nas escolas refletem excelente nível de acesso tanto a equipamentos de TV, vídeo e bibliotecas, como à Internet. Há bibliotecas em mais de 80\% das escolas consultadas, mas uma percentagem idêntica ou ainda maior possui salas-de-aula dotadas de microcomputadores. Tal infraestrutura constitui importante fonte de pesquisa para os alunos. Embora a existência de hardware seja em si mesma promissora, considerou-se que extrapolaria os objetivos do projeto a identificação dos programas disponíveis oficialmente nas escolas; assim, optou-se pela elaboração de ferramentas de edição de apresentações baseadas em programas freeware ou shareware. Uma discussão sobre tal escolha encontra-se em Carneiro e Barbosa (2002a).

\section{Conhecimentos prévios de Geociências}

Carneiro (1997) realizou levantamento preliminar sobre o domínio de conceitos geológicos de professores da rede estadual de ensino de $1^{\circ}$ Grau (denominação vigente na época, atual ensino fundamental) na região de Jundiaí. Embora seja uma amostra pouco representativa, ela reflete aspectos relevantes da lacuna entre o conhecimento disponível sobre a região estudada e os conhecimentos de Geologia de que alguns docentes dispunham para suas aulas.
Esses dados orientaram a obtenção de informações geológicas, geomorfológicas e de risco associado à ocupação urbana local, e evidenciaram a necessidade de se fornecer fontes que atendessem a alguns pré-requisitos que facilitassem abordagens específicas sobre a região estudada.

Na pesquisa, relatada mais detalhadamente por Barbosa (2003), quatro temas disponíveis para escolha são específicos da própria região:

1. riscos de acidentes naturais e ocupação urbana;

2. Geologia e evolução geológica da região de JundiaíAtibaia;

3. relevo da região de Jundiaí-Atibaia e problemas de ocupação urbana;

4. estudos do meio e trabalhos de campo na região de Jundiaí-Atibaia.

Somente o último deles, porém, foi incluído entre os mais "pontuados". Pode-se explicar esse fato pela falta de elementos de suporte que capacitem os professores a explorar essas informações sobre a própria região em que os professores vivem. Sugere-se que persista certa carência de conceitos fundamentais de Geologia.

\section{Estudos do meio e trabalhos de campo}

A realização de estudos do meio seria outro modo de se minimizar a deficiência em conceitos geológicos básicos acima referida, mas essa atividade dificilmente poderia ser autônoma, pois dependeria da capacidade de leitura de mapas temáticos, pelo professor, em uma área formada, sobretudo, por rochas proterozóicas, além da dificuldade de tratamento técnico de relatórios geológicos.

Para propiciar um primeiro contato dos docentes com roteiros específicos, evitou-se a inclusão de mapas geológicos, mas foram fornecidas fotografias de rochas e paisagens típicas da área, como subsídios para ensino de campo em Geologia. O recurso de inserir esses elementos em uma apresentação de microcomputador parece trazer vantagens, embora a passividade das fotografias as torne desestimulantes para estudo prático de rochas. Esta etapa de trabalho desembocou na elaboração de quatro roteiros de campo para viagens de curta duração, dos quais um, mais simples, destinase a alunos dos níveis de ensino fundamental ou médio e três destinam-se ao nível superior. Um foi testado e avaliado por alunos de Geologia Estrutural, enquanto os demais ainda não foram aplicados (Oliveira e Carneiro, 2001, 2002).

O material contido no CD-ROM procurou favorecer a participação mais ativa do professor e do aluno, segundo papéis que Barbosa (2003) denominou "professor-autor" e "aluno-autor". O formato que prevê maior flexibilidade de papéis didáticos associados ao computador no ensino 
parece ser aquele no qual, em certa medida, o professor passe a figurar como "autor" do próprio material que utilizará. Isso é facilitado por ferramentas que permitam elaboração de apresentações (seqüências lineares de telas de computador combinando texto e imagem). Ao mesmo tempo, o caráter aberto de uma ferramenta de apresentação dá flexibilidade para diferentes faixas etárias e características dos alunos.

É escassa a oferta, no mercado editorial, de material didático dirigido ao professor, na forma de ilustrações préelaboradas. Assim, a produção de editores de seqüências, para que o próprio professor possa elaborar suas aulas ou abrir espaço para o trabalho orientado dos alunos, é uma possibilidade com grande potencial de êxito. Pretende-se investigar, desse modo, a oferta de um uso "fechado" do computador e confrontá-lo com um uso mais "aberto". O material "aberto" daria liberdade de ação para o professor e para o aluno e ampliaria as oportunidades para desenvolvimento da pesquisa. Ambas as opções são interessantes, cabendo à pesquisa subseqüente avaliar qual delas se mostra mais produtiva (ou promissora).

\section{CONCLUSÕES}

Nos últimos dois séculos, uma das áreas do saber que menos cresceu foi a arte de ensinar (Meis et al., 1997), ou seja, a forma de se transmitir aos jovens o saber acumulado pela sociedade. Ao mesmo tempo, ampliou-se significativamente o volume anual de artigos que se acrescentam ao saber universal. O professor da educação básica precisa continuamente assimilar esses conceitos novos, para atualizar-se, em um trabalho "generalista". São cada vez mais necessários, portanto, os especialistas capazes de decodificar conceitos básicos a partir da grande massa de informações disponíveis. Boa parcela deles encontra-se nas próprias universidades.

O projeto denominado Geo-Escola revelou ser viável elaborar materiais didáticos a partir de informações obtidas em projetos especializados de investigação e mapeamento geológico. O módulo aqui descrito, Jundiaí-Atibaia, Estado de São Paulo, ainda não concluído, vem sendo conduzido junto a docentes de Geografia e Ciências de ensino fundamental. O conjunto de escolas participantes da pesquisa na região divide-se da seguinte forma: $3 / 4$ de escolas públicas (75,5\%) e 1/4 de escolas particulares (24,5\%). A análise indicou que alta percentagem de docentes utiliza recursos audiovisuais, atingindo 93,5\% da amostra. O interesse por novos recursos é igualmente alto, permitindo-se admitir perspectivas muito boas de sucesso no incentivo ao uso do computador como ferramenta educativa.

O módulo de CD-ROM educacional, fornecido aos professores da região, buscou avaliar a utilidade dos materiais didáticos para:
1. aproveitamento, em sala-de-aula, de dados básicos sobre a história geológica da região e sua dinâmica ambiental;

2. estudo das relações do homem com o planeta em diferentes escalas, especialmente considerando-se a região onde os professores vivem ou exercem seu trabalho educativo;

3. avaliação da alternativa de se incrementar estudos de campo (os chamados estudos do meio) com base em informações de natureza geológica.

A pesquisa revelou que pode e deve ser estimulado nessas disciplinas o estudo de aspectos particulares da região onde os alunos vivem. Sob esse aspecto particular, a aplicação prática desse tipo de investigação pode ocorrer em muitas outras situações geológicas e regiões brasileiras, aproveitando-se as magníficas condições naturais e a variedade de ambientes existentes no país. Embora favorecido pela excelente receptividade para inclusão de temas de Geociências em aulas, ainda não se coletaram dados confiáveis sobre o grau de autonomia de que dispõem os professores para tomar tal decisão (Barbosa, 2003), mas vislumbrou-se a possibilidade de que tais produtos possam contribuir para atribuição de novos papéis a professores e alunos: as figuras do "professor-autor" e "aluno-autor". Esse aspecto também deverá ser mais investigado.

\section{AGRADECIMENTOS}

Os autores agradecem a dois anônimos revisores, pelas pertinentes sugestões, que muito contribuíram para aprimorar o manuscrito.

\section{REFERÊNCIAS BIBLIOGRÁFICAS}

ALMEIDA, F. F. M. Fundamentos geológicos do relevo paulista. Boletim do Instituto Geografia e Geologia, São Paulo: SEPLAN, n. 41, p. 167-263, 1964.

BARBOSA, R. Projeto Geo-Escola: recursos computacionais de apoio ao ensino de geociências nos níveis fundamental e médio. 2003. 105p. + CD-ROM. Dissertação (Mestrado em Geociências) - Instituto de Geociências, Universidade Estadual de Campinas, Campinas.

BRASIL. Ministério da Educação. Secretaria de Educação Média e Tecnológica. Parâmetros curriculares nacionais: ensino médio. Brasília: Ministério da Educação, 1999. 364 p.

CAMPOS, D. A. O ensino das ciências da Terra. In: SIMPÓSIO A IMPORTÂNCIA DA CIÊNCIA PARA O DESENVOLVIMENTO NACIONAL, 1., 1997, São Paulo. 
Documentos... São Paulo: Academia Brasileira de Ciências, 1997. $1^{\text {a }}$ Sessão: Educação, p. 39-46.

CARNEIRO, C. D. R. (Ed. Científico). Geologia. São Paulo: Global: SBPC - Projeto Ciência Hoje na Escola, 2000. 80 p. (Série Ciência Hoje na Escola, 10).

CARNEIRO, C. D. R. Estruturas planares e vulnerabilidade das rochas à erosão na região de Campo Limpo - Francisco Morato, SP. In: SIMPÓSIO NACIONAL DE ESTUDOS TECTÔNICOS, 7., 1999, Lençóis; INTERNATIONAL SYMPOSIUM ON TECTONICS OF THE BRAZILIAN GEOLOGICAL SOCIETY, 1., 1999, Lençóis. Anais... Lençóis: SBG - BA, 1999. Seção 6, p. 29-33.

CARNEIRO, C. D. R. Geologia da região de JundiaíAtibaia. Projeto Evolução Crustal da Região de JundiaíAtibaia e implicações conceituais para ensino de campo em geologia e planejamento da ocupação. Campinas: IG UNICAMP, 2001. 90 p. + 9 anexos (3 mapas). Relatório Científico Final, FAPESP/CNPq.

CARNEIRO, C. D. R. Projeto de Pesquisa Evolução Crustal da Região de Jundiaí-Atibaia e implicações conceituais para ensino de campo em geologia e planejamento da ocupação. Campinas: IG - UNICAMP, 1997. 14 p. + anexos. Relatório Científico Parcial para a FAPESP, 1.

CARNEIRO, C. D. R.; BARBOSA, R. A simple didactic tool for stimulating the use of computers in Geology Education. In: INTERNATIONAL CONFERENCE ON GEOSCIENCES EDUCATION, 4., 2003, Calgary. Conference proceedings... Calgary: GeoSciEd IV Org. Committee/IGEO, 2003. p. 25-26.

CARNEIRO, C. D. R.; BARBOSA, R. Demandas de conocimiento de geociencias por profesores de Ciencias y Geografia: el ejemplo de Jundiaí-Atibaia, São Paulo, Brasil. In: SIMPOSIO DE LA ENSEÑANZA DE LA GEOLOGÍA, 12., 2002, Girona. Actas... Girona: AEPECT, 2002a. Documentos de Trabajo, p. 47-57.

CARNEIRO, C. D. R.; BARBOSA, R. Geo-Escola: apoio em temas geocientíficos para docentes de Ciências e Geografia no nível fundamental em Jundiaí-Atibaia, SP. In: CONGRESSO BRASILEIRODE GEOLOGIA, 41., 2002, João Pessoa. Anais... João Pessoa: SBG, 2002b. p. 568, apresentação pôster S19-02.

CARNEIRO, C. D. R.; TOLEDO, M. C. M.; ALMEIDA, F. F. M. Dez motivos para a inclusão de temas de Geologia na Educação Básica. Revista Brasileira Geociências, v. 34, n. 4, p. 553-560, 2004.
CARNEIRO, C. D. R.; SILVA, A. B.; REGINATO, M. Towards a dynamic digital cartography: GIS-aided geologicalgeotechnical mapping of the Jundiaí-Atibaia region, São Paulo State, Brazil. In: INTERNATIONAL GEOLOGICAL CONGRESS, 31., 2000, Rio de Janeiro. Abstracts... Rio de Janeiro: IUGS, 2000. Presented 08 Aug. 2000, booth G51, section 22-2.

CARNEIRO, C. D. R.; SOUZA, J. J. Mapeamento geomorfológico em escala de semidetalhe da região de Jundiaí-Atibaia. Revista Brasileira Geomorfologia, v. 4, n. 2, p. 17-30, 2003.

DURBIN, J. M. The benefits of combining computer technology and traditional teaching methods in large enrollment lecture classes. Journal of Geosciences Education, v. 50, n. 1, p. 56-63, 2002.

INSTITUTO DE PESQUISAS TECNOLÓGICAS DO ESTADO DE SÃO PAULO. Mapa geomorfológico do Estado de São Paulo, ao milionésimo. São Paulo: IPT, 1981. 2 v. (IPT Monografias 5).

MEIS, L.; LETA, J.; LANNES, D. O ensino de ciências face à explosão do saber. In: SIMPÓSIO A IMPORTÂNCIA DA CIÊNCIA PARA O DESENVOLVIMENTO NACIONAL, 1., 1997, São Paulo. Documentos... São Paulo: Academia Brasileira de Ciências, 1997. 1ª Sessão: Educação, p. 29-37.

OLIVEIRA, E. A. F.; CARNEIRO, C. D. R. Roteiros de campo para ensino de geologia, a partir de levantamentos geológicos e geomorfológicos da região de Jundiaí-Atibaia. In: CONGRESSO INTERNO DE INICIAÇÃO CIENTÍFICA, 9., 2001, Campinas. Resumos... Campinas: UNICAMP, 2001. p. 70-71. 1 CD-ROM.

OLIVEIRA, E. A. F.; CARNEIRO, C. D. R. Roteiros didáticos de campo em geologia, baseados em mapas geológicos e geomorfológicos da região de Jundiaí-Atibaia. In: CONGRESSO INTERNODE INICIAÇÃO CIENTÍFICA, 10., 2002, Campinas. Resumos... Campinas: UNICAMP, 2002. 1 CD-ROM.

PARDO, M. Nuevas herramientas de comunicación electrónica en la enseñanza presencial: el aula virtual de geología. Revista de la Enseñanza de las Ciencias de la Tierra, v. 9, n. 1, p. 28-35, 1996.

PASCHOALE, C.; FREITAS, H. C. L.; FRACALANZA, H.; AMARAL, I. A.; TESSLER, M. G. A geologia e a escola de $1^{\circ}$ e $2^{\circ}$ graus. In: SIMPÓSIO NACIONAL SOBRE O ENSINO DE GEOLOGIANO BRASIL, 1., 1981, Belo Horizonte. Teses. 
Belo Horizonte: SBG, 1981. v. 1, p. 157-167.

PINTO, V.; FONT, X.; CASAS, A. Utilización de diferentes herramientas software para la enseñanza de la Geología Ambiental. Revista de la Enseñanza de las Ciencias de la Tierra, v. 6, n. 3, p. 264-169, 1998.

PRO-SCIENTIÆ - NJR/ECA/USP. Carta de São Paulo em defesa da divulgação científica. Boletim eletrônico ProScientice, n. 16, ago. 2002. Especial 1. Congresso Internacional de Divulgação Científica. Disponível em:

http://www.eca.usp.br/nucleos/njr/proscientiae/ numero16.htm. Acesso em: 04 set. 2002.

SOUZA, J. J.; CARNEIRO, C. D. R. Confecção de mapa geomorfológico da região de Jundiaí-Atibaia por meio da utilização de SIG. In: CONGRESSO BRASILEIRO DE GEOLOGIA, 41., 2002, João Pessoa. Resumos... João Pessoa: SBG, 2002a. p. 145. Apresentação oral.

SOUZA, J. J.; CARNEIRO, C. D. R. Mapa geomorfológico, em ambiente SIG, da região de Jundiaí-Atibaia. In: CONGRESSO INTERNODE INICIAÇÃO CIENTÍFICA, 10., 2002, Campinas. Resumos... Campinas: UNICAMP, $2002 \mathrm{~b}$. 1CD-ROM.

TEIXEIRA, W.; TOLEDO, M. C. M.; FAIRCHILD, T. R.; TAIOLI, F. Decifrando a Terra. São Paulo: Oficina de Textos, 2000.567p.

TOLEDO, M. C. M. Geologia/Geociências no ensino. In: SEMINÁRIO NACIONAL SOBRE CURSOS GRADUAÇÃO EM GEOLOGIA, 2., 2002, Campinas. Campinas: Universidade Estadual de Campinas. 2002. Apresentação oral. 